Check for updates

Cite this: Energy Adv., 2022,

1,7

DOI: 10.1039/d2ya90001g

rsc.li/energy-advances

\section{Editorial introducing Energy Advances}

\author{
Volker Presser (D)
}

Dear readers, it is our great pleasure to introduce the first issue of Energy Advances, published by the Royal Society of Chemistry (RSC). The birth of a new journal is an exciting time that brings opportunity and possibilities. In the words of Hermann Hesse: Magic dwells in each beginning. Indeed, the progress in energy technology and materials has been nothing short of astonishing, but the challenges ahead of us towards a sustainable future remain equally breathtaking. In this Editorial, we'd like to highlight some of the reasons why Energy Advances is a great place to showcase your work.

Energy materials and technology are key assets and essential instruments for sustainability. The highly multidisciplinary nature of energy research and the global scope of the challenges mandate collaboration. Bold new visions and indepth understanding of processes and mechanisms are complemented by the need for technology transfer on a large scale (no electric car runs on just one self-made coin cell). Our vision for Energy Advances is to be an inclusive space for everyone working to tackle global energy sustainability challenges. We welcome studies that expand our horizons across the wide range of energy research, from battery technologies, energy storage,

Leibniz Institute for New Materials, Germany.

E-mail: presser@presser-group.com catalysis \& fuels; to topics at the intersection of disciplines, taking inspiration from other branches of science \& engineering, or advancing our progress towards the UN Sustainable Development Goals (https://sdgs.un.org/goals). In particular, we welcome contributions to new discoveries and novel materials just as much as high-quality work that helps us understand processes better, that deal with techno-economical and sustainability analysis, and digital energy research topics!

Of course, the Royal Society of Chemistry already has a strong and demonstrable reputation for excellence in the energy sciences, evident through our sister journals Energy \& Environmental Science, Journal of Materials Chemistry A and Sustainable Energy \& Fuels - perhaps you already saw our cross-journal collection showcasing battery-focused research (http://rsc.li/batteries).

Energy Advances will underpin these titles as the RSC's first fully Gold Open Access energy science journal. This step is very exciting to us at the RSC, especially in the light of a research landscape that has been transformatively changed both by digitalization and the global pandemic. With less physical contact possibilities to meet and exchange ideas and work, high-quality journals with reliable peer-review have become ever more important! Energy Advances supports you to disseminate your research with no barrier to access. So we are covering the article processing charges (APCs) for authors, making it free to publish Open Access in our journal until mid-2024; helping you benefit from the widest possible readership at no cost.

We are committed to ensuring that Energy Advances meets the needs of the communities it is designed to serve, and we strive to provide a venue that caters not only for your Open Access needs, but also the fast times to decision, robust highquality peer review, and dedicated customer service that you should expect from a trusted society publisher like the RSC. And to facilitate that, we are delighted to

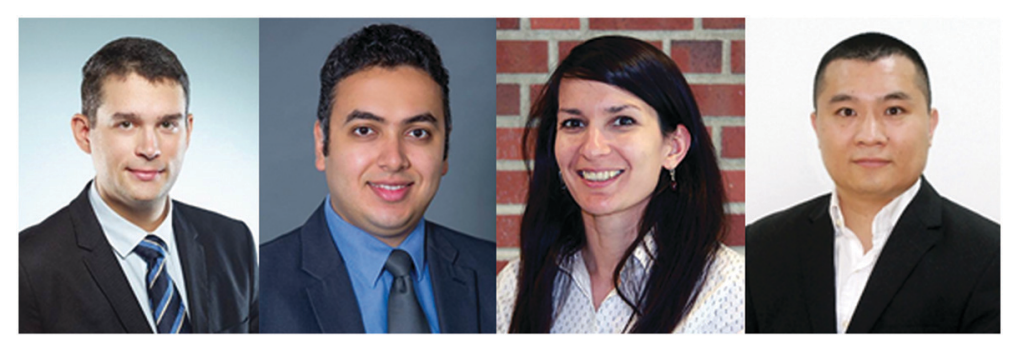


welcome Michael Naguib (Tulane University, USA), B. Layla Mehdi (University of Liverpool, UK) and Guang Feng (Huazhong University of Science and Technology, China) as our inaugural Associate Editors, who will handle the peer review of submissions to the journal. Our team welcomes your future submissions to the journal and are excited to discover more about the research you are conducting. You can find out more about the journal's Editorial team at http://rsc.li/ energyadvances-board and can submit your work to our Associate Editors online at https://mc.manuscriptcentral. com/energyadv.
How else can you get involved? As well as publishing with us, you can read our first articles as soon as they are available online (https://pubs.rsc.org/en/journals/ journalissues/ya\#!recentarticles\&adv). We hope that you'll spread the word about these articles to your colleagues and networks. You might also be interested in watching an online event discussing the perspectives, challenges, and opportunities for next-generation battery research (https://youtu.be/68BvxKhTvsw). This event formed part of the RSC's activities supporting COP26 in October 2021, highlighting how the chemical sciences have a key role in tackling sustainability challenges.
In this inaugural issue, we have papers covering topics from redox flow battery technology, to polymer electrolyte fuel cells - we look forward to bringing you more diverse and innovative research in future issues. Sign up to receive future issue alerts at http://rsc.li/alerts.

We look forward to bringing you lots of exciting research in the journal in 2022 and beyond, and welcome you as potential future authors, reviewers, and readers.

Best wishes, Volker Presser, Editor-in-Chief Emma Eley, Executive Editor 